\title{
METÁSTASIS INTRAESCROTAL DE UN CARCINOMA RENAL
}

\author{
J. CALLEJA ESCUDERO, M. PASCUAL SAMANIEGO, S. MARTÍN BLANCO, \\ C. DE CASTRO OLMEDO, V. GONZALO, E. FERNÁNDEZ DEL BUSTO
}

Servicio de Urología. Hospital Clínico Universitario. Valladolid.

Actas Urol Esp. 28 (4): 311-313, 2004

\section{RESUMEN}

METÁSTASIS INTRAESCROTAL DE UN CARCINOMA RENAL

Comunicamos un caso, infrecuente, de metástasis intraescrotal de un carcinoma renal. Se trata de un paciente varón de 66 años, sometido a nefrectomía radical con cavotomía por un carcinoma de células renales con infiltración en la vena renal y trombo en cava. Seis meses después, consultó por la aparición de unos nódulos intraescrotales y en raíz de pene. El paciente falleció 15 meses después de la nefrectomía. Habitualmente las metástasis intraescrotales son un evento tardío después de la detección del carcinoma renal.

PALABRAS CLAVE: Intraescrotal. Metástasis. Carcinoma renal.

\section{ABSTRACT \\ INTRASCROTAL METASTASIS IN A RENAL CELL CARCINOMA}

The present article reports a case of intrascrotal metastasis of renal adenocarcinoma. This is an unusual case. A 66-year-old male patient undewent right radical nephrectomy and cavotomy for renal cell carcinoma with renal vein infiltration and thrombus in cava. Six months later the patient present with a nodulous enlargement intrascrotal and roots of penis. And he died 15 moths after nephrectomy. Usually intrascrotal metastases are a late event in the course after detection of a renal carcinoma.

KEY WORDS: Intrascrotal. Metastasis. Renal cell carcinoma.

$\mathrm{E}^{\prime}$ carcinoma renal representa el $2 \%$ de las neoplasias malignas del adulto, siendo el tercer tumor en frecuencia de los tumores del aparato genitourinario. En España se diagnostican entre 1.500 y 2.000 nuevos casos al año, lo que supone 4-4,5 casos por cada 100.000 varones y año y 1,6-2,2 por cada 100.000 mujeres y año ${ }^{1}$.

El 30\% de los enfermos con carcinoma de células renales tienen metástasis en el momento del diagnóstico, siendo los sitios más frecuentes el pulmón, los ganglios linfáticos, los huesos, el hígado, la glándula suprarrenal y el cerebro ${ }^{2}$. En algunos estudios, la afectación pulmonar es más frecuente que la ganglionar.
Las metástasis solitarias del carcinoma de células renales pueden ser el motivo de consulta en pacientes con tumor primario asintomático.

Las metástasis en el pene o los testículos son inusuales. En el pene ${ }^{3}$ se pueden presentar como priapismo o induración peneana difusa, secundaria a infiltración del cuerpo cavernoso.

Las metástasis intraescrotales son un hallazgo excepcional y un evento tardío después de la detección de un carcinoma renal primario $^{4}$. El primer caso de metástasis testiculares de un carcinoma renal ${ }^{5}$ fue descrito por Bandler en 1964. 


\section{CASO CLÍNICO}

Paciente de 66 años de edad, ex-fumador, con antecedentes de intervención de pólipo adenomatoso en colon, hernia inguinal y varices esofágicas, que fue ingresado para estudio por una anemia crónica hipocrómica microcítica y tos persistente.

La analítica presentaba una hemoglobina de $10,2 \mathrm{~g} / \mathrm{dl}$, hematocrito de $33 \%$ y una velocidad de sedimentación globular de 87 . El sistemático de orina y la radiografia de tórax fueron normales.

La ecografía abdominal mostraba una masa hiperecoica en la cortical del riñón derecho de $7 \mathrm{x}$ 5,6 x 6,6 cm, compatible con tumoración sólida.

En la TAC abdominal se apreciaba una masa renal derecha en polo inferior, sugestiva de hipernefroma de $10 \mathrm{~cm}$ de diámetro, que producía trombosis de la vena renal y vena cava inferior. También se evidenciaba adenopatías locorregionales. El estudio de extensión no evidenció metástasis.

Con el diagnóstico de hipernefroma se realizó nefrectomía ampliada derecha con cavotomía y extracción de trombo tumoral, así como linfadenectomía interaorto-cava.

La anatomía patológica fue de carcinoma de células renales del tipo de células claras de $8 \mathrm{~cm}$ de diámetro con invasión tumoral del uréter y de la vena renal. Grado nuclear III/IV. Ganglios sin afectación tumoral (T3bNO).

Tres meses después de la cirugía, la radiografía de tórax mostraba múltiples imágenes nodulares en ambos campos pulmonares compatibles con metástasis. Además presentaba un dolor radicular en la pierna izquierda. El paciente fue tratado con Interleukina-2 por el Servicio de Oncologia.

Seis meses después de la cirugía consultó por la aparición de dos nódulos irregulares, duros de 2-3 cm de diámetro, situados por debajo del teste derecho, en la raíz del pene (Fig. 1). La ecografía escrotal informaba de una masa extratesticular ecogénica, sólida con pequeñas áreas quísticas de $2,3 \times 2,5 \times 2 \mathrm{~cm}$ y otra formación de características similares en la raíz peneana de $2,8 \times 2 \mathrm{~cm}$ (Fig. 2).

Se realizó PAAF de dichas lesiones resultando el diagnóstico anatomopatológico de metástasis por carcinoma de células claras.

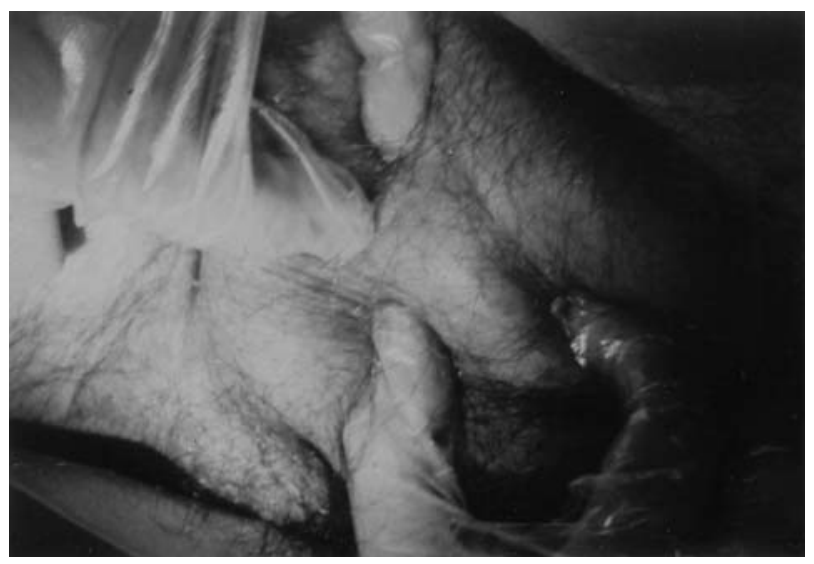

FIGURA 1. Palpación de nódulos irregulares por debajo de teste derecho y raiz de pene.

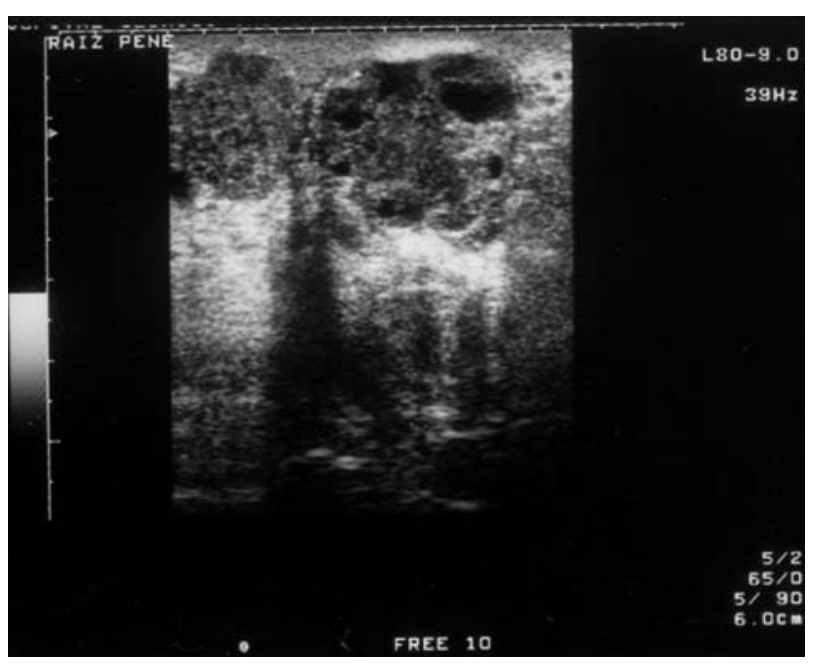

FIGURA 2. Ecografia escrotal en la que se aprecia tumoración ecogénica, extratesticular sólida y con áreas quisticas.

En la TAC de control se apreciaba una masa paravertebral bilateral, que infiltraba la vértebra a nivel C7-D1, por la que precisó la administración de radioterapia antiálgica.

Catorce meses después de la cirugía, fue tratado con radioterapia paliativa por sindrome de compresión medular, falleciendo un mes más tarde.

\section{DISCUSIÓN}

La patología metastásica escrotal, excluyendo leucemias y linfomas que pueden afectar secundariamente al testículo, es rara.

La incidencia de metástasis testiculares en series de autopsias varía entre el 0,06 y el 0,46\%, siendo el carcinoma de próstata el tumor primitivo 
más frecuente ${ }^{5}$. Hasta la actualidad se han descrito 21 casos de metástasis testiculares de un carcinoma renal $^{6}$, la mayoría con afectación ipsilateral. También se han descrito 19 casos de metástasis localizadas en el cordón espermático y en el epidídimo ${ }^{7}$.

La diseminación tumoral puede ser hematógena y/o linfática ${ }^{8}$. Hay dos vías diferentes de diseminación hematógena ${ }^{4}$ :

Por un lado la cascada de la vía arterial. Previamente establecidas las metástasis pulmonares, circulando a través de las cavidades cardíacas izquierdas, alcanzando el contenido escrotal con el flujo sanguíneo arterial.

Por otro lado por el sistema venoso ${ }^{4,9}$. En caso de obstrucción de la vena renal por un trombo tumoral, la suelta de células malignas puede producirse por sistemas venosos colaterales y a través de la vena espermática alcanzan el contenido escrotal por flujo retrógrado. El varicocele sintomático es también consecuencia de la obstrucción venosa causada por el tumor. La siembra a través del plexo de Batson y las venas vertebrales no puede ser excluida como vía de diseminación, sobre todo en casos de afectación escrotal contralateral ${ }^{10}$ y a pesar del hecho de que las venas vertebrales no se anastomosan normalmente con la vena espermática.

Se han descrito metástasis testicular hasta 7 años después de la nefrectomía radical. Habitualmente son ipsilaterales y del lado izquierdo.

La presencia de metástasis en los genitales conlleva un pobre pronóstico, ya que en muchas ocasiones se acompaña de metástasis múltiples (supervivencia de un 5-10\% a 5 años) como ocurrió en nuestro caso. Cuando la metástasis es única, la extirpación de la misma mejora considerablemente el pronóstico (supervivencia a 5 años de $29-35 \%)^{11}$.

\section{REFERENCIAS}

1. ALONSO J, CAMACHO E, RICO J.: Carcinoma renal. En: Patología urogenital. Ediciones Mayo 2003: 173-186.

2. LAURO S, LANZETTA G, BRIA E, TRASATTI L, COSTARELLI L, VECCHIONE A.: Contralateral solitary testis metastasis antedating renal cell carcinoma: a case report and review. Anticancer Res 1991; 18 (6B): 4683-4684.

3. DANIELS GF, SCHAEFFER AJ.: Renal cell carcinoma involving penis and testis: unusual initial presentations of metastatic disease. Urology 1991; 37 (4): 369-373.

4. DIECKMANN KP, DÜE W, LOY V.: Intrascrotal metastasis of renal cell carcinoma. Eur Urol 1988; 15: 297-301.

5. DATTA MW, ULBRIGHT TM, YOUNG RH.: Renal cell carcinoma metastatic to the testis and its adnexa: a report of fives cases including three that accounted for the initial clinical presentation. Int $J$ Surg Pathol 2001; 9 (1): 49-56.

6. PATEL SR, RICHARDSON RL, KVOLS L.: Metastatic cancer to the testes: a report of 20 cases and review of the literature. J Urol 1989; 142: 1003-1005.

7. FOURNIER G, HUBERT J, CHASSAGNE S, MENUT P, DELAVIERR D, MANGIN P. Metastases d'adénocarcinome rénal au niveau du cordon spermatique et de l'épididyme: deux observations. Prog Urol 1995; 5: 714-716.

8. BLASCO M, LLARENA R, ACHA M et al.: Metástasis testicular de adenocarcinoma renal presentación de un caso. Arch Esp de Urol 1994; 47 (3): 281-282.

9. FALLICK ML, LONG JP, UCCI A.: Metachronous renal cell carcinoma metastases to spermatic cord and penis. Scand J Urol Nepro 1997; 131: 299300.

10. RIESE W, WARMBOLD H, AEIKENS B.: Intrascrotal metastases from renal cell carcinoma. Int Urol Nephrol 1986; 18 (4): 449-452.

11. THRASHER JB, PAULSON DF.: Prognostic factors in renal cancer. Urol Clin N Am 1993; 20: 247-262.

Dr. J. Calleja Escudero

C/ Domingo Martínez, $6-7^{\circ} \mathrm{B}$

47007 Valladolid

(Trabajo recibido el 23 junio de 2003) 